\title{
Constrained crystallization of poly(L-lactic acid) in thin films prepared by dip coating
}

Marylène Vayer, Alain Pineau, Fabienne Warmont, Marjorie Roulet, Christophe

Sinturel

Interfaces, Confinement, Matériaux et Nanostructures (ICMN), CNRS-Université d'Orléans, UMR 7374, 1b, Rue de la Férollerie, C.S. 40059, 45071 Orléans Cedex 2, France

\section{Corresponding Author}

marylene.vayer@univ-orleans.fr

\section{Graphical abstract}

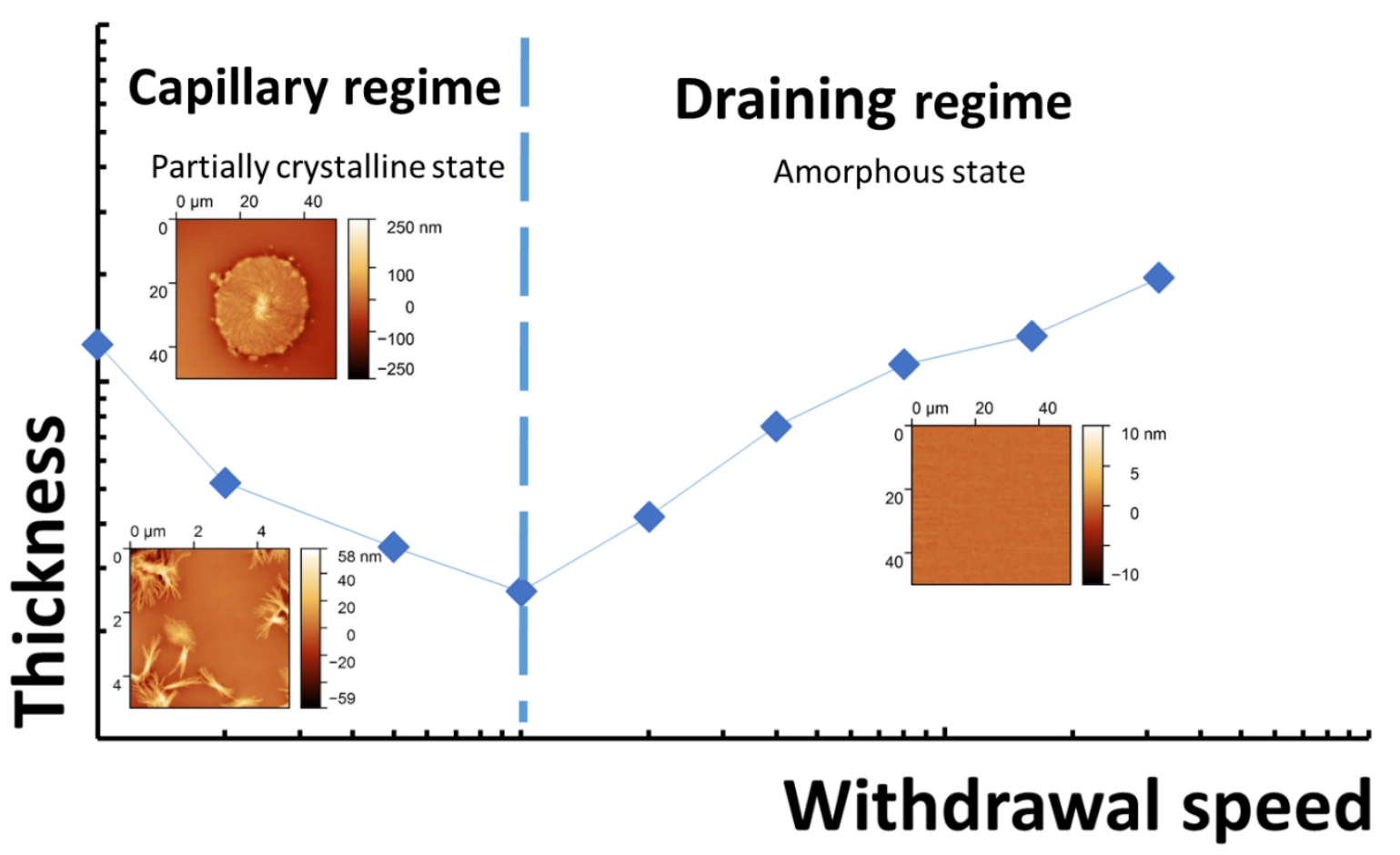




\section{Abstract}

Dip coating process used at various withdrawing speeds showed a great ability to control the crystalline structure of thin films of poly(L-lactic acid) which can be of great importance for applications where mechanical or optical properties are involved. Thin films were studied by Atomic Force Microscopy and Grazing Incidence Angle X-ray Diffraction. Withdrawing the silicon substrate in the draining regime (at high speed) led to amorphous films with flat surface whatever the solvent and the molar mass. At low speeds (capillary regime), AFM demonstrated the presence of spherulites or hedrites in the films depending on the solvent and the molar mass. GIXRD showed that spherulites were less crystallized than hedrites. This difference was attributed to solvent evaporation rate.

\section{Introduction}

The crystallinity of polymers in coatings is of great importance since it affects their physical properties and their efficiency in many applicative fields such as organic electronic [1-3] and packaging [4]. Consequently, the control and the understanding of the crystallization of polymers in thin films is still an academic and economic challenge [5-8].

Poly(L-lactic acid) (PLLA) is a crystalline biodegradable polymer with low toxicity and is a good material for packaging and medical devices [9]. PLLA is a polymer with high rigidity and biocompatibility. Crystallization of this polymer has been the subject of numerous studies [10-18] and the control of the crystallization in thin film is still challenging [19].

Crystallization of PLLA thin films is generally achieved by thermal cooling under isothermal conditions [20]. However, some studies have considered the case of non-isothermal conditions although processing conditions are more complex and do not respond to the general rules developed for isothermal conditions [10, 21]. Androsch and Iqbal have studied the case of the cooling of a melt of PLLA at constant cooling rate [10]. In this case, it has been shown that the resulting morphology depends on the cooling rate and the molar mass. Fast cooling is known to inhibit crystallization. Udagawa et al. have studied the thermal annealing induced crystallization of PLLA films between 50 and $600 \mathrm{~nm}$ thick onto PVA layer and have shown that crystallization of thin film depends on the thickness of the film and could be non-homogeneous in the thickness of the film, with a restricted crystallization close to the substrate side due to the affinity of the polymeric chains toward the substrate [20]. 
Crystallization of PLLA film induced by immersion or vapor exposure in organic solvents has recently become the object of a growing interest. Sato et al. have studied the crystallization of $40 \mu \mathrm{m}$ amorphous thick films of PLLA immerged in organic solvents, and have demonstrated the relationship between crystallization degree, solubility and swelling [22]. The crystallization degree depends on the degree of swelling (higher swelling degree leads to higher crystallization degree). Naga et al. have shown that crystallization can be obtained by vapor exposure of amorphous PLLA films with acetone [19]. Wu et al. have studied the solvent vapor exposure of ultra-thin film $10 \mathrm{~nm}$ thick of PLLA deposited on Au substrate and compared the efficiency to provoke crystallization of acetone, dichloromethane and chloroform [23, 24]. Acetone and chloroform lead to crystallization whereas dichloromethane leads to an amorphous layer. They have attributed this difference of behavior to the difference of affinity of the solvent toward PLLA. Co-crystallization of PLLA with some organic solvents has been also studied by some authors [25-27] and leads to original form of crystallization. Lan and $\mathrm{Li}$ have studied the effect of $\mathrm{CO}_{2}$ on the crystallization of PLLA [28]. Crystallization induced by solvent evaporation has been also considered and concerns the crystallization of polymer during the formation of films by methods using a polymer solution and solvent evaporation such as spin coating or dip coating. The literature is much less abundant on this subject and rarely concerns PLLA. For another polymer (PEO), Toolan et al. have studied the crystallization induced by evaporation of the solvent during the formation of the film by spin coating onto glass substrate [6]. The resulting morphology depends on the depth of the quench when the film is prepared using spin coating. If the solvent is lost rapidly, the morphology is frozen far away from the thermodynamic equilibrium (and vice-versa). In this last case, the polarity of the solvent influences the crystalline morphology of spin-coated PEO thin film [6].

To our knowledge, studies of crystallization during dip coating are only studied by Rogowski and Darhuber, who have examined the crystallization of nicotinamide in isopropanol during the formation of the film by dip coating onto glass slides or silicon wafer [29]. They have demonstrated that the obtained morphology depends on the withdrawal rate. At low rate, they have proposed that a supersaturated zone near the contact line exists and that nucleation and crystals growth proceed in this zone. This suggest that dip-coating could be used to control the crystallization of polymer thin films but this has not been reported yet.

In this paper, we studied the crystallization of thin films of PLLA during the process of films formation by dip-coating onto silicon wafer. Crystallization is dramatically influenced by substrate roughness and wettability. Silicon wafer was chosen as substrate for this study since 
it is completely flat. The surface energy of the polymer $\left(39 \mathrm{~mJ} . \mathrm{m}^{-2}\right)$ is lower than the surface energy of the chosen substrate (silicon wafer $\left(49 \mathrm{~mJ} . \mathrm{m}^{-2}\right)$ ). All the chosen solvents have

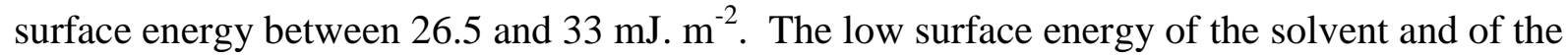
polymer compared to the substrate allows to have a good wettability of the solution.

The influences of molar mass of polymer, deposition regime (withdrawal speed) and nature of the solvent used for the solution of the polymer were examined. We demonstrated that the crystallinity of the film was mainly governed by the evaporation rate of the used solvent and the withdrawal speed.

\section{Experimental}

\section{Materials:}

Two poly(L-lactic acid) (PLLA), acid end-cap, named PLLA 323K and PLLA 100K with molar masses (Mn of 323,386 and 100,273 g. mol ${ }^{-1}$ ) were purchased from Akina, Inc. and used without purification. All the used solvents were purchased from Sigma Aldrich and used as received.

$\operatorname{Si}(100)$ substrates of $10 * 60 \mathrm{~mm}^{2}$ were cleaned by sonication in dichloromethane, methanol and distilled water for 10 minutes each.

\section{Polymers thin film solutions:}

Solutions of PLLA were prepared at room temperature $\left(21^{\circ} \mathrm{C}\right)$ by dissolving the adequate mass of polymer in solvent (1,4-dioxane (dioxane), 1,2-dichloroethane (DCE), or dichloromethane (DCM) to obtain a concentration of polymer of $20 \mathrm{mg} \cdot \mathrm{mL}^{-1}$. The solutions were stirred at room temperature for at least 2 hours.

\section{Dip-coating procedure:}

The films were prepared at room temperature by dip-coating Si substrates using a homemade equipment. The container of the polymers solution was a $10 \mathrm{~mL}$ graduated cylinder, halffilled up to $40 \mathrm{~mm}$ high. The dimensions of the graduated cylinder were: $75 \mathrm{~mm}$ high and 17 $\mathrm{mm}$ internal diameter. The Si substrate was immersed in the solution on $40 \mathrm{~mm}$ high and was left immersed for one minute. This time allowed all perturbations due to the immersion of the substrate to be fully damped. Then, the substrate was pulled out at constant speed between 1 to $300 \mathrm{~mm} \cdot \mathrm{min}^{-1}$. 


\section{Thickness evaluation:}

The film thickness was evaluated using an interference-based film thickness measurement system for the flat film (F20, Filmetrics). When the film was too rough, an average thickness was determined using AFM images of a scratched area of the film.

\section{Atomic force microscopy images:}

Atomic Force Microscopy (AFM) images were collected using a Bruker Dimension Icon in contact mode.

\section{Grazing incidence X-ray diffraction:}

Grazing incidence X-ray diffraction (GIXD) was performed on a PHILIPS parallel beam horizontal diffractometer using $\mathrm{Cu}-\mathrm{K} \alpha$ source (1.54056 $\AA$ ). The information depth depends on the incidence angle. Use of a $0.17^{\circ}$ incidence angle allowed for the structural investigation of the polymer layer (information depth of $13 \mathrm{~nm}$ (depth for 63\% signal)). Angles were measured with a $0.03^{\circ}$ precision. The angles are given after refraction correction.

\section{Results and Discussion}

\section{Thickness as a function of the withdrawal speed}




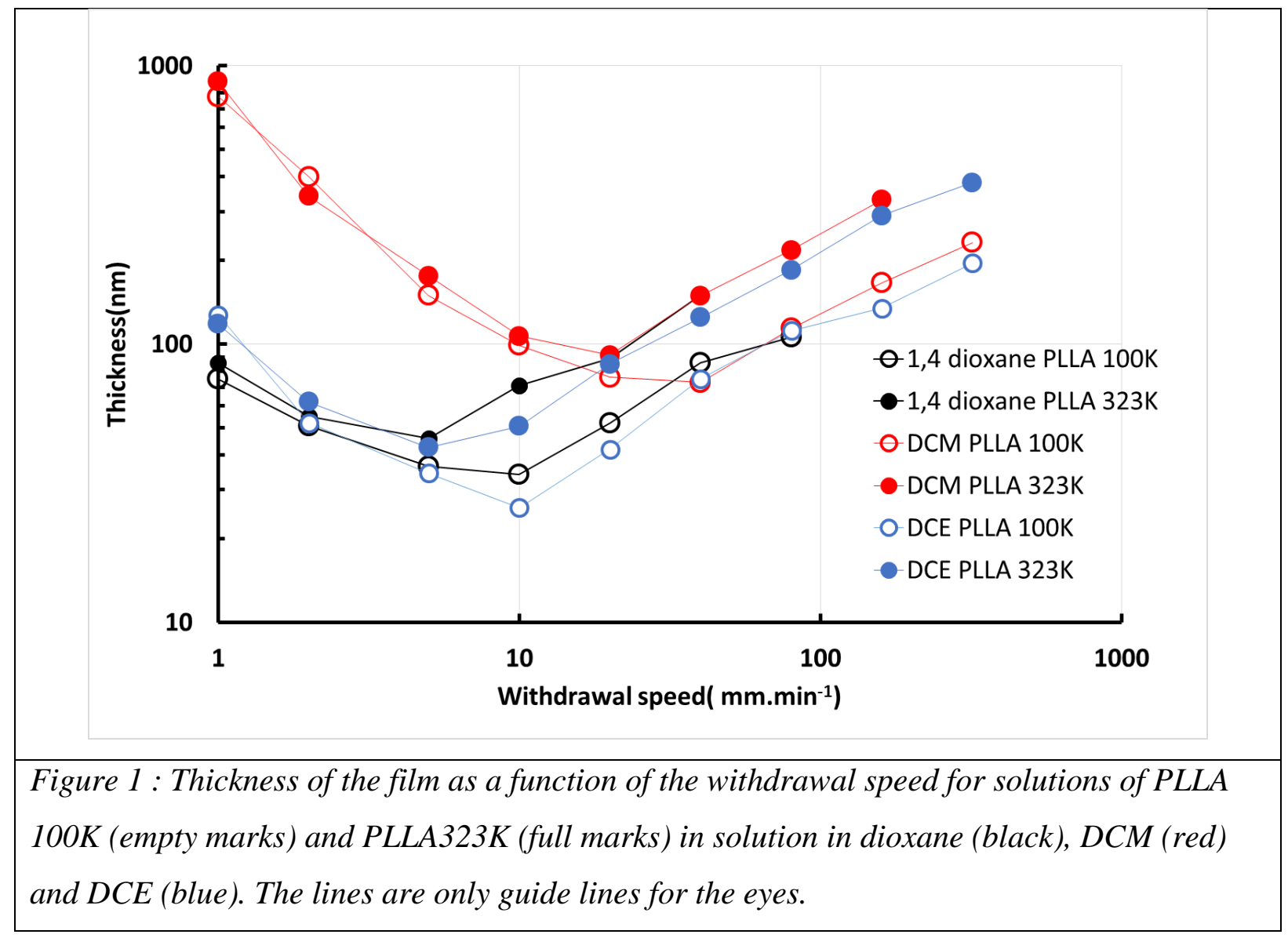

As shown in Figure 1, the thickness of the studied film $\left(h_{f}\right)$ depends on the withdrawal speed $\left(\mathrm{U}_{\mathrm{o}}\right)$. As proposed by Faustini [30] this dependence can be rationalized as follows:

$$
\mathrm{h}_{\mathrm{f}}=\mathrm{k}_{\mathrm{i}}\left(\frac{\mathrm{E}}{\mathrm{L}} \frac{1}{\mathrm{U}_{0}}+\mathrm{D} \mathrm{U}_{0}^{2 / 3}\right)
$$

where $k_{i}$ depends on the weight concentration of the polymer in the solution $\left(c_{i}\right.$ in $\left.g / \mathrm{cm}^{3}\right)$ and the density of the polymer $\left(\rho_{\mathrm{i}} \mathrm{g} / \mathrm{cm}^{3}\right)$ by $\mathrm{k}_{\mathrm{i}}=\mathrm{c}_{\mathrm{i}} / \rho_{\mathrm{i}}$. E, L, D are the evaporation speed, the film width and the global draining constant $\mathrm{D}$.

At low withdrawal speed (capillary regime), the thickness is proportional to the inverse of the speed and proportional to the evaporation rate of the solvent. As shown in Figure 1, in this regime, the curves for the two PLLA are superposed for a given solvent, which is logical as the evaporation rate depends mainly on the solvent nature. Moreover, as the evaporation rate increases with vapor pressure $\left(\mathrm{P}_{0} \mathrm{DCM}(573 \mathrm{hPa})>\mathrm{P}_{0} \mathrm{DCE}(87 \mathrm{hPa})>\mathrm{P}_{0}\right.$ dioxane $(38 \mathrm{hPa})$ at $20{ }^{\circ} \mathrm{C}$ ), the evaporation rate is higher for DCM than for DCE and dioxane. Consequently, the films exhibited thicknesses in the order DCM > DCE > dioxane. 
At high withdrawal speed (draining regime), the thickness is proportional to the withdrawal speed at the $2 / 3$ power. This was confirmed since all the curves (in log-log scale) exhibited the same 2/3 slope in this regime. As we can see on Figure 1, in this regime the curves for all the PLLA 100K solutions are superposed. Similarly, the curves for all the PLLA 323K solutions are superposed. The films obtained with this polymer (PLLA323K) were thicker than those obtained with the polymer with lower molecular mass. This can be explained with the draining constant since this constant depends on the viscosity, the surface tension and the density of the solution. In our case, the viscosity of the solution was greatly affected by the molecular mass of the polymer. This implied that the thickness was lower for lower molar mass (see Figure 1 the superposition of the three curves of PLLA 323K and the three curves of PLLA $100 \mathrm{~K})$.

Between these two regimes, the thickness curve as a function of the withdrawal speed exhibited a minimum for a critical speed. Its literal expression was calculated by derivation of the equation (1) and is expressed as follows:

$$
U_{c}=\left(\frac{3}{2} \frac{E}{L D}\right)^{3 / 5}
$$

As shown in Figure 1, the critical speeds are lower for DCE and dioxane than for DCM and lower for PLLA $323 \mathrm{~K}$ than $100 \mathrm{~K}$. This was easily explained by the dependences of $U_{c}$ with $E$ ${ }^{3 / 5}$ with $E_{D C M}>E_{D C E}>E_{\text {dioxane }}$ that implied $U_{c \text { DCM }} \gg U_{c \text { DCE }}>U_{c}$ dioxane and of $U_{c}$ on $D^{-3 / 5}$ with D PLLA 323K $>$ D PLLA 100K (solutions with PLLA 323K being more viscous than solutions with PLLA $100 \mathrm{~K}$ ) that implied $\mathrm{U}_{\mathrm{c}}$ PLLA $323 \mathrm{~K}<\mathrm{U}_{\mathrm{c}}$ PLLA $100 \mathrm{~K}$.

\section{Morphology of the films}

\section{Description of the typical morphologies}

The film morphology was studied by AFM. The AFM scan size was chosen in order to have an overall view of the surface features. Figure 2 displays the three typical morphologies observed for the dip coated films (Figure 2a, 2c, 2e). Figure 2b, 2d, 2f are images of the corresponding films with a scratch in order to confirm the presence of polymer in the featureless zones.

Figures $2 \mathrm{a}$ and $2 \mathrm{~b}$ display AFM images of dip-coated film at $320 \mathrm{~mm} \cdot \mathrm{min}^{-1}$ from a solution of PLLA $323 \mathrm{~K}$ solution in DCE. The film was $380 \mathrm{~nm}$ thick and the surface exhibited a 
featureless, flat morphology with a RMS roughness less than $1 \mathrm{~nm}$. No sign of crystallization was herein observed.

Figures $2 \mathrm{c}$ and $2 \mathrm{~d}$ display AFM images of dip-coated film at $1 \mathrm{~mm} \cdot \mathrm{min}^{-1}$ from a solution of PLLA 323K solution in DCM. A circular feature, $30 \mu \mathrm{m}$ in diameter, $100 \mathrm{~nm}$ high on the edge and $200 \mathrm{~nm}$ high in the center, with radially organized fibers was observed. This feature was observed within a flat amorphous polymeric layer of $800 \mathrm{~nm}$ thick as confirmed by the scratched image. This morphology was attributed to the formation of a spherulite in the amorphous layer as proposed by others [7, 31]. Spherulites originate from the crystallization of polymers and are constituted of an alternation of crystalline and non-crystalline regions [32-33].

Dip coated film of PLLA 323K solution in DCE at $10 \mathrm{~mm} \cdot \mathrm{min}^{-1}$ exhibited other characteristic structures similar to bundles of fibers (Figures $2 b, 2 d$ ). These structures are observed for an early stage of growth of spherulites and depending on the stage of development, they are denominated hedrites or sheaf [34]. In this study, we did not distinguish between hedrites and sheafs and called them hedrites. As seen in Figure 2e, the hedrites had on surfaces two types of configuration, edge-on or flat-on (marked with an arrow). Like the spherulites, theses hedrites were embedded within a flat polymeric layer, as demonstrated by the image of the scratched area, which was in this case $40-50 \mathrm{~nm}$ thick. The hedrites led to features $30 \mathrm{~nm}$ high, edge-on and $15 \mathrm{~nm}$ high flat-on.

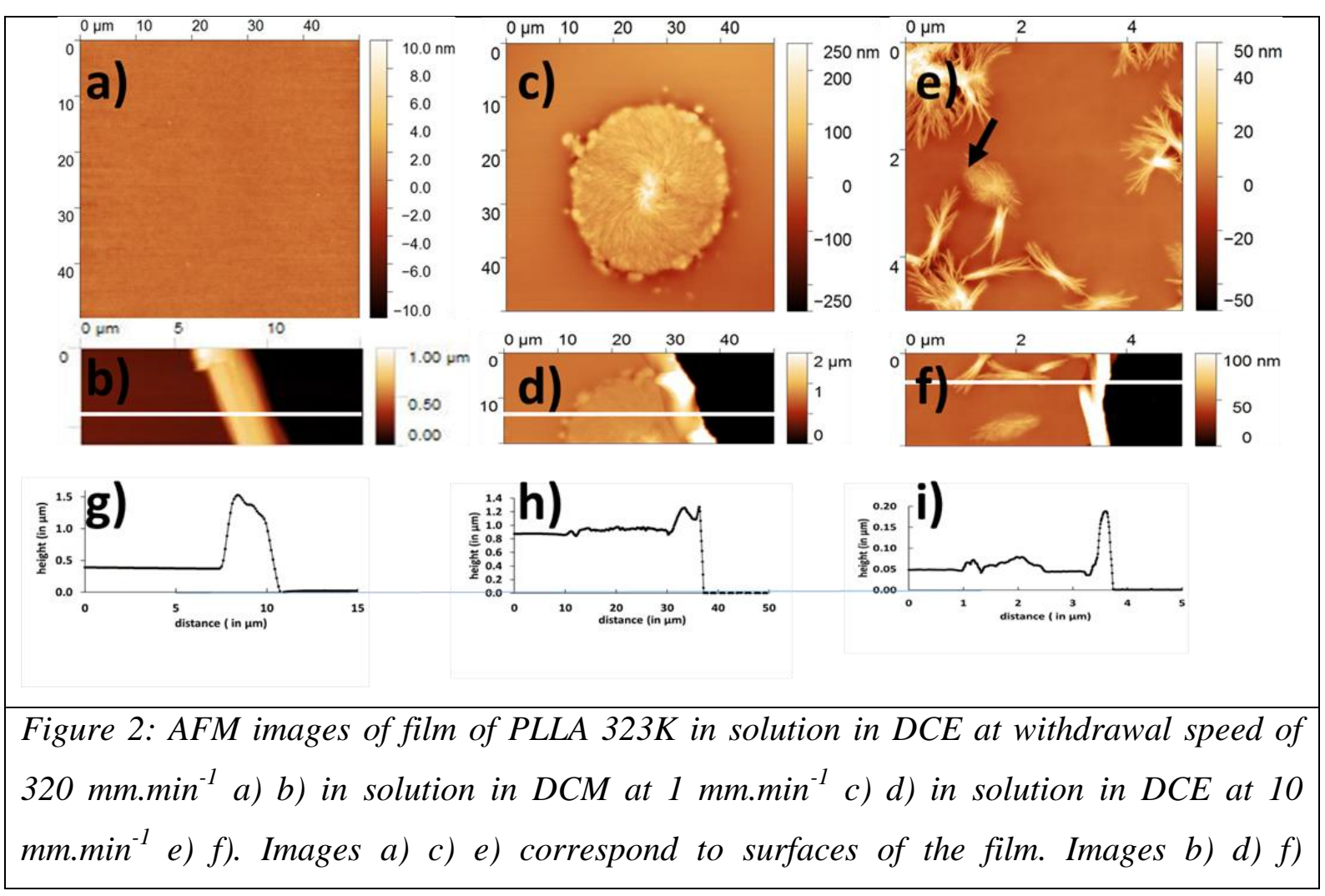


correspond to scratched areas. Graphs $g$ ) h) i) are the corresponding height sections along the white lines drawn in images $b$ ) d) f).

\section{Morphology as a function of the withdrawal speed}

In the following, we illustrate the influence of the withdrawal speed by considering a PLLA $100 \mathrm{~K}$ in solution in DCE at $20 \mathrm{mg} \cdot \mathrm{mL}^{-1}$ (Figure 3). Other results using dioxane or DCM and PLLA 323K in DCE are shown in supplementary material SM 1- 5. For withdrawal speeds from 320 down to $80 \mathrm{~mm} \cdot \mathrm{min}^{-1}$, the film surfaces exhibited a featureless, flat morphology with a RMS roughness less than $1 \mathrm{~nm}$. For withdrawal speed equal to $20 \mathrm{~mm} \cdot \mathrm{min}^{-1}$ the surface exhibited hedritic structures in a flat polymeric layer. As the withdrawal speed decreased, the crystalline structures grew and spread over the surface of the flat layer. For withdrawal speeds of 1 and $2 \mathrm{~mm} \cdot \mathrm{min}^{-1}$, the whole surface of the polymer film was fully covered by impinging spherulites. It is interesting to note that when the structures (hedrites or spherulites) were observed (withdrawal speed less than $40 \mathrm{~mm} \cdot \mathrm{min}^{-1}$ ), the surface density (number of crystalline features per area) did not change with the withdrawal speed (this density was estimated to 80 per $10000 \mu \mathrm{m}^{2}$ ). However, the size of these structures grew from $0.15 \mu \mathrm{m}$ at $20 \mathrm{~mm} \cdot \mathrm{min}^{-1}$ up to $6 \mu \mathrm{m}$ at $5 \mathrm{~mm} \cdot \mathrm{min}^{-1}$. At lower withdrawal rates, the size was limited by impingement of the structures. It is important to note that all thicknesses were different and followed a V shaped curve (with a minimum thickness observed around $10 \mathrm{~mm} \cdot \mathrm{min}^{-1}$ ). We comment this aspect later in the discussion. 


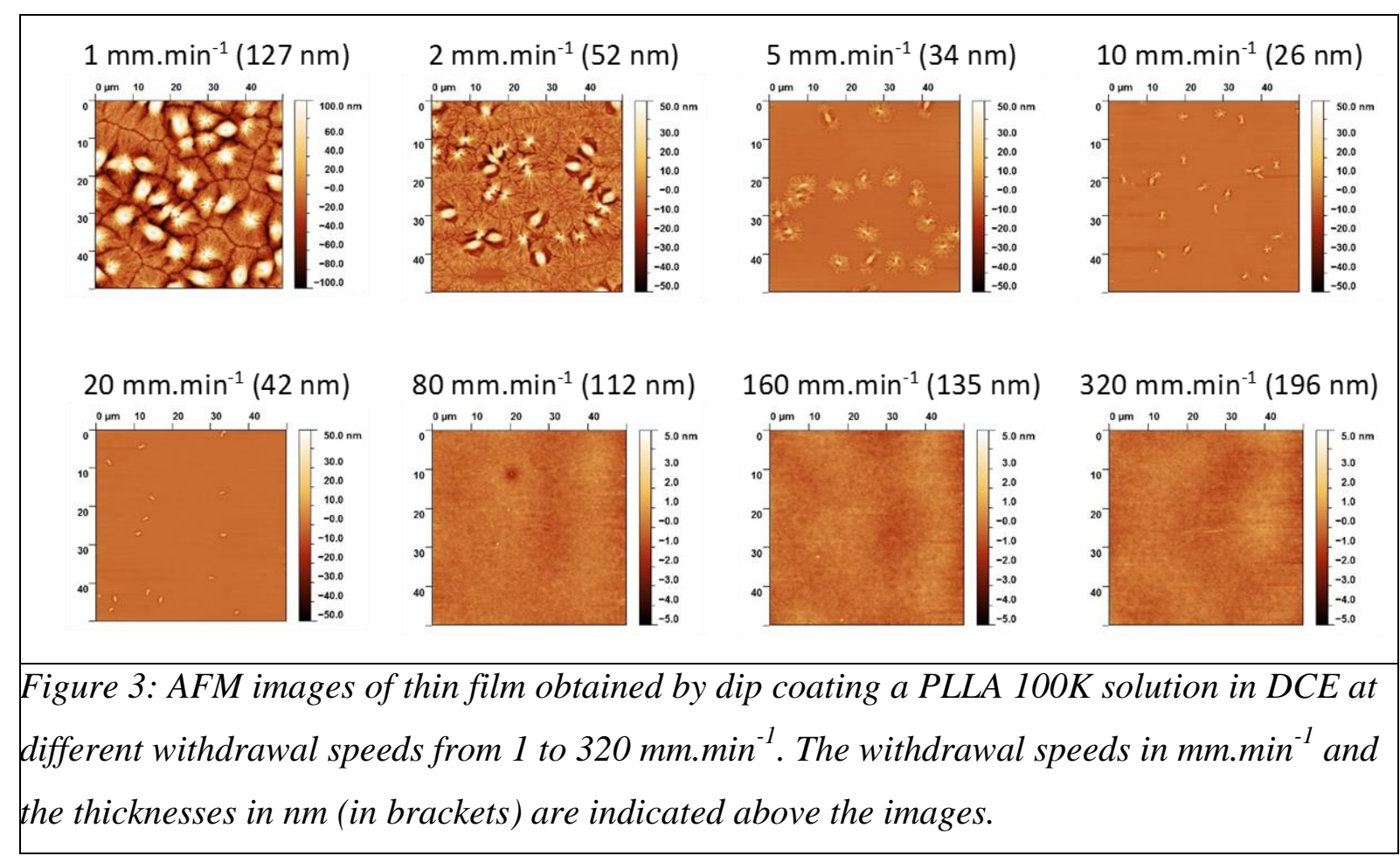

\section{Morphology as a function of the solvent nature}

Figures 4 and 5 display the obtained morphologies at low $\left(2 \mathrm{~mm} \cdot \mathrm{min}^{-1}\right)$ and high withdrawal speeds $\left(80 \mathrm{~mm} \cdot \mathrm{min}^{-1}\right)$ for the three solvents and the two molar masses.

Let us consider the case of the low withdrawal speed $\left(2 \mathrm{~mm} \cdot \mathrm{min}^{-1}\right)$. For DCM, dip coated samples exhibited sparely dispersed spherulites in a flat layer as shown in Figure 4. These spherulites were about $15 \mu \mathrm{m}$ in diameter for PLLA $323 \mathrm{~K}$ and $30 \mu \mathrm{m}$ in diameter for PLLA 100K. For DCE, spherulites were more numerous and more packed for PLLA 323K than for PLLA 100K. These spherulites were in contact together, which led to non-circular shape. For dioxane, the formed structures were hedrites. As for DCE, these structures were more numerous and more packed for PLLA 323K than for PLLA 100K.

At $80 \mathrm{~mm} \cdot \mathrm{min}^{-1}$, no crystalline structures were detected on the surface of the flat layer whatever the molar mass and the solvent nature. However, some differences of morphology were noted. The film obtained from dioxane exhibited some holes at the surface of the film (Figure 5) whereas the films obtained from DCE and DCM did not present such features. These holes indicated a partial dewetting of the film from the substrate or a non-adhesion of the film onto the substrate as exemplified in the optical microscope images in supplementary material (Figure SM 6). 

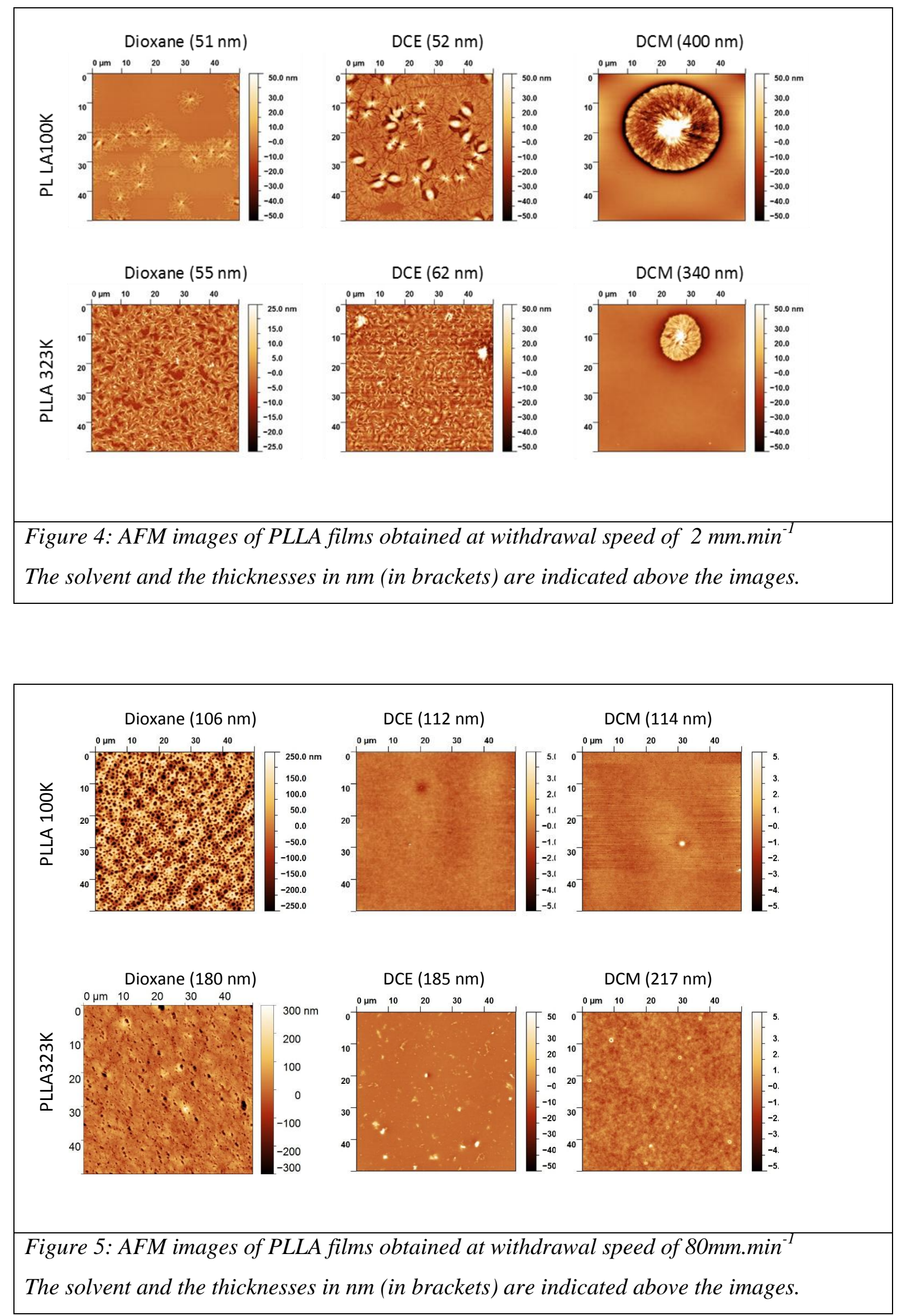
To summarize this section on the morphological analysis of the film, for the three tested solvents and for the two tested polymer molar masses, the morphology of the film evolved globally in the same way as a function of the withdrawal speed. For speeds less than 20 $\mathrm{mm} \cdot \mathrm{min}^{-1}$, the number of structured features (hedrites or spherulites) was independent of the withdrawal speed. However, the coverage of the film surface by theses structured features increased when the withdrawal speed decreased. Additional images in supplementary material SM 1-5 confirm this trend. Speeds higher than $80 \mathrm{~mm} \cdot \mathrm{min}^{-1}$ led to flat polymeric layers or dewetting.

\section{Grazing Incidence X-ray Diffraction analysis}

Crystallization of the films was investigated by Grazing Incidence X-ray Diffraction analysis. Figure 6 displays the diffractograms of the films using GIXRD at $0.17^{\circ}$ incidence angle. For the films obtained by dip-coating at $1 \mathrm{~mm} \cdot \mathrm{min}^{-1}$, films prepared with DCE and dioxane solutions exhibited diffraction peaks visible at 16.8 and $18.9^{\circ}$. The assignment of theses peaks is detailed in the discussion chapter. The diffraction peaks had the same position for PLLA $100 \mathrm{~K}$ and $323 \mathrm{~K}$ with a higher intensity for PLLA $100 \mathrm{~K}$ than PLLA $323 \mathrm{~K}$. This leads to the conclusion that the films prepared in these conditions were at least partially crystallized. For DCM solution of PLLA $100 \mathrm{~K}$ the films obtained by dip-coating at $1 \mathrm{~mm} \cdot \mathrm{min}^{-1}$ presented no visible diffraction peaks. The films of PLLA 323K prepared with DCM at $1 \mathrm{~mm} \cdot \mathrm{min}^{-1}$ led to a broad diffraction peaks at $16.1^{\circ}$. The crystallinity of the films is discussed later. For all the films obtained by dip-coating at $80 \mathrm{~mm} \cdot \mathrm{min}^{-1}$ and higher speeds, no diffraction peak was observed leading to the conclusion that the films were amorphous in these conditions. This is exemplified in Figure 6 for the case of PLLA 100K in DCM at $320 \mathrm{~mm} \cdot \mathrm{min}^{-1}$. 


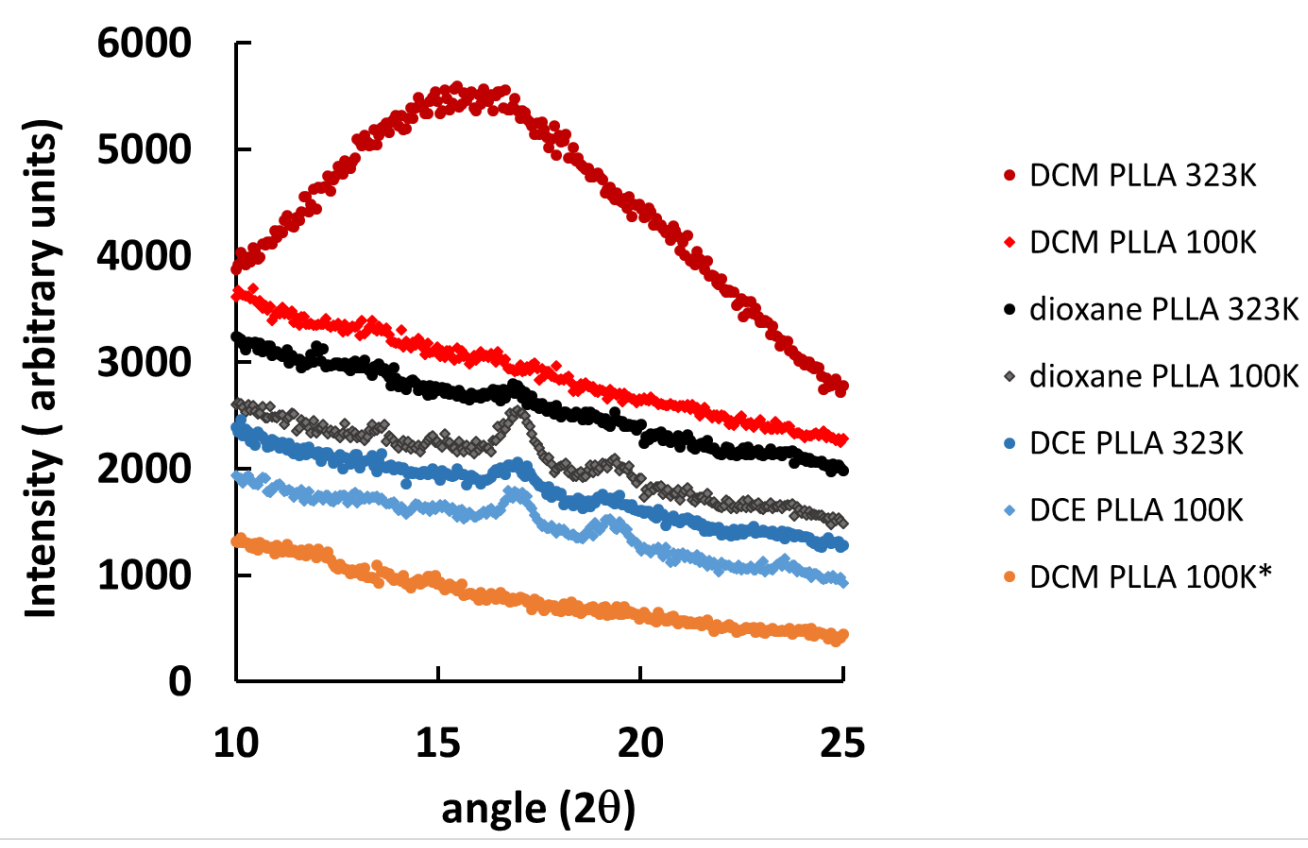

Figure 6: GIXRD diffractograms of the films of PLLA thin films obtained by dip coating solution in DCE, dioxane or DCM at $1 \mathrm{~mm} . \mathrm{min}^{-1}$ (except DCM PLLA $100 \mathrm{~K}$ * obtained at $320 \mathrm{~mm} . \mathrm{min}^{-1}$ ). All the diffractogramms in counts per second are translated (except DCM PLLA 100K) in order to clarify the figure. Supporting materials SM7 provides a figure with the raw data.

\section{Post-treatments: Thermal annealing and solvent vapor exposure of dip coated films}

In this section, we examine the evolution of films dip coated at withdrawal rate higher than 80 $\mathrm{mm} \cdot \mathrm{min}^{-1}$ submitted to 2 different post-treatments (thermal annealing and solvent exposure). These thin films initially presented a flat surface in AFM (Figure 7a) and a flat diffractogram (Figure 8) without any diffraction peak which was a signature of an amorphous state. Figure 7 and 8 present the case of a PLLA 100K film prepared by dip coating a DCE solution at 160 $\mathrm{mm} \cdot \mathrm{min}^{-1}$. A first film was thermally annealed for 5 minutes at different temperatures between $40^{\circ} \mathrm{C}$ and $180^{\circ} \mathrm{C}$ and quenching at room temperature. Annealing under the glass transition $\left(60^{\circ} \mathrm{C}\right)$ leads to no modification of the surface morphology (see supporting materials SM8). After heating between the glass transition $\left(60^{\circ} \mathrm{C}\right)$ and the melting temperatures $\left(180^{\circ} \mathrm{C}\right)$, the surface was completely covered by small features as shown in Figure $7 \mathrm{~b}$. Annealing above the melting temperatures $\left(180^{\circ} \mathrm{C}\right)$ and quenching to room temperature leads to no features observation of the surface. 
The Figure 8 displays the GIXRD diffractogram of this sample, which exhibited in the studied range only one intense narrow diffraction peak at $16.5^{\circ}$. This attested the crystalline state of this film.

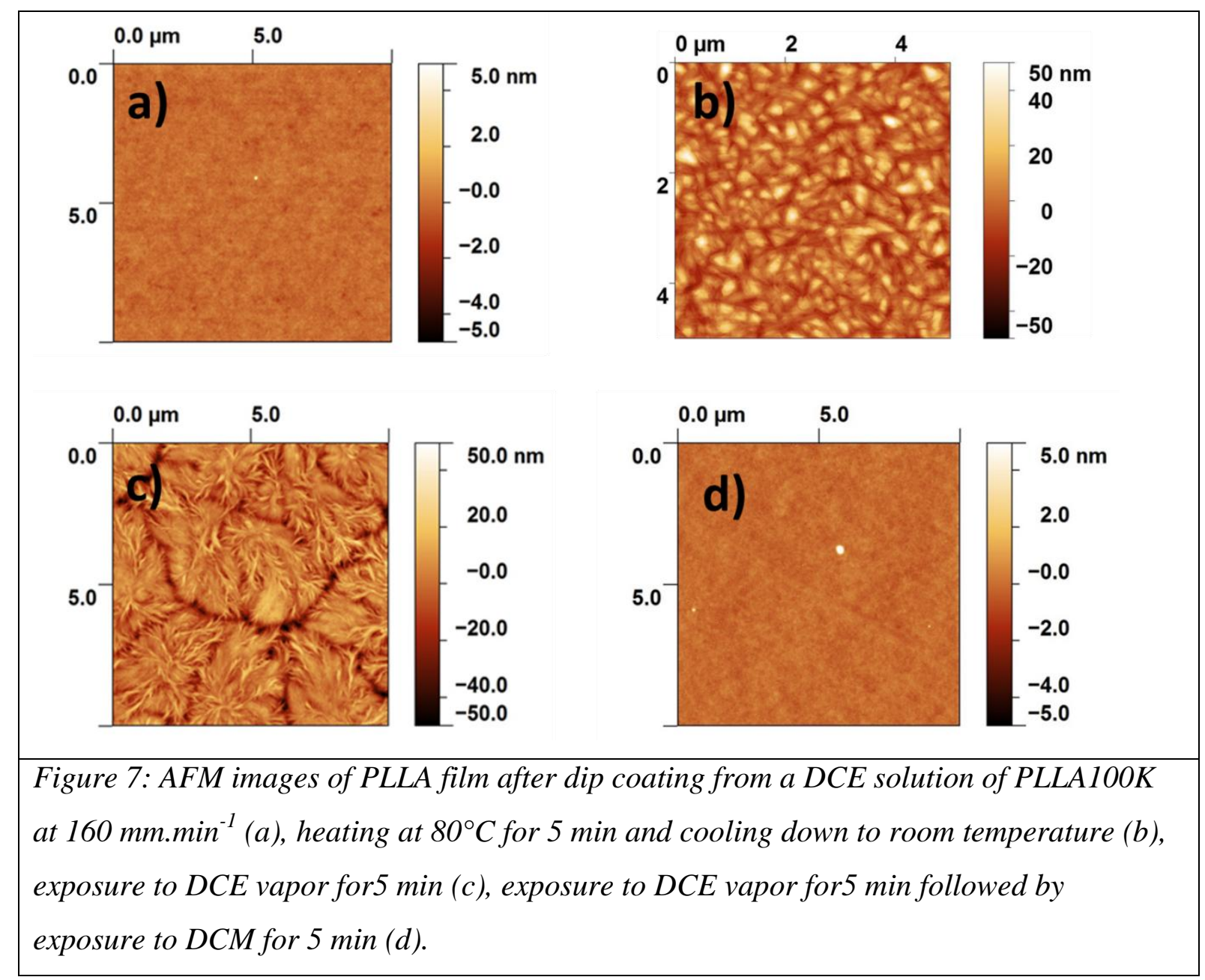




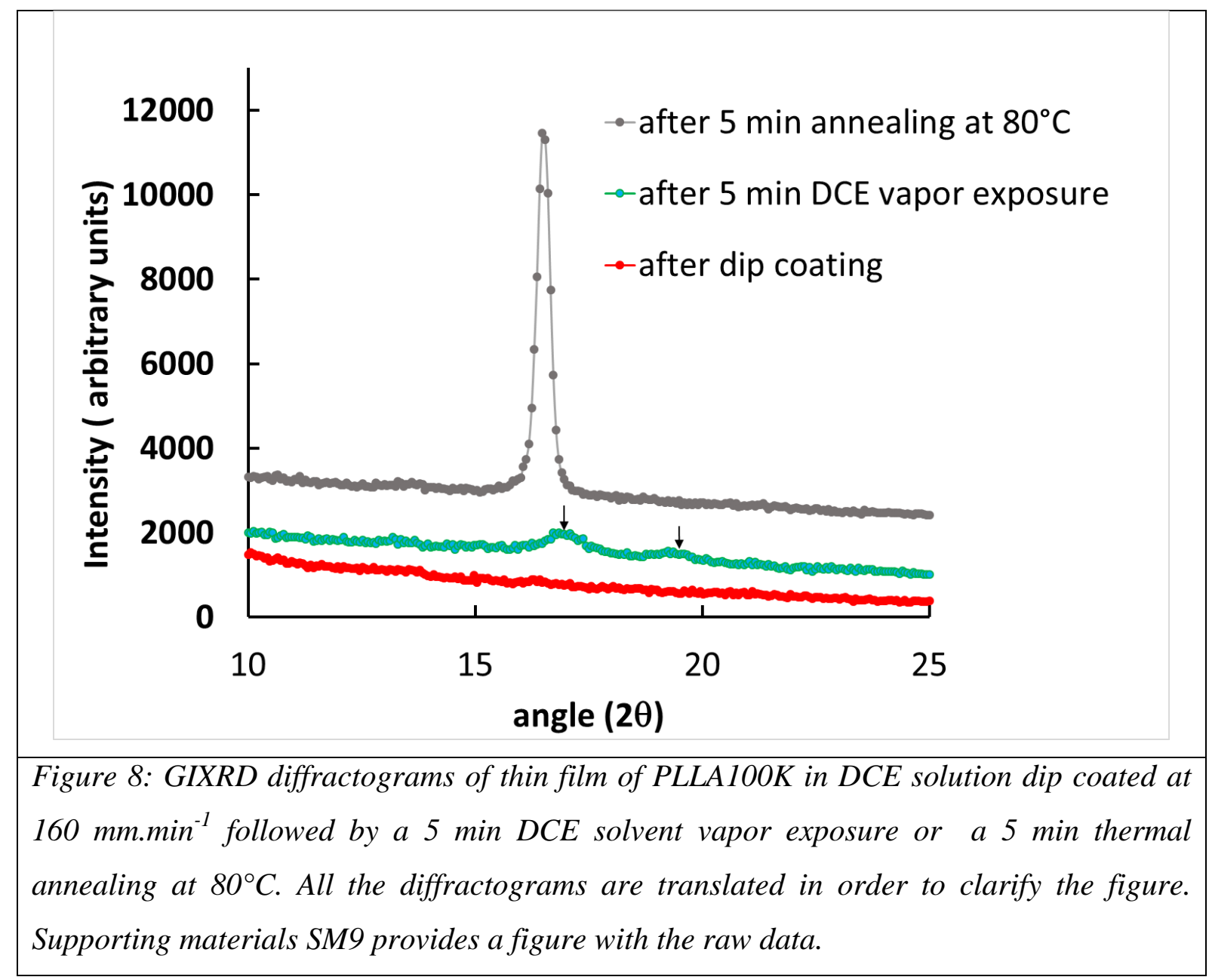

We also undertook successive DCE and DCM vapor exposures of a second film with a flat surface and a flat diffractogramm (same morphology as Figure 7a). Figure 7 presents typical images of solvent vapor exposure of this dip-coated sample. The supporting materials SM10 presents all the AFM images. Exposures to DCE solvent vapor for $5 \mathrm{~min}$ or longer led to a surface completely covered with spherulites as shown in Figure 7c. The grain boundaries were clearly visible. The obtained morphology was similar to the one obtained for dip coating from a solution of DCE at low withdrawal rate. The diffractogram of this sample in Figure 8 presents two diffraction peaks in the same position $\left(17.2\right.$ and $\left.19.4^{\circ}\right)$ as those observed for DCE dip coated sample at low withdrawal rates. Further DCM exposure of this sample ruled out all these structures leading to a flat amorphous surface (Figure 7d). Exposure again to DCE 5 min led again to a surface completely covered with spherulites (same AFM images than Figure 7c). This cycle (DCE exposure / DCM exposure) leading to flat amorphous surface/ surface totally covered by spherulites was repeated at least 4 times. 


\section{Discussion}

Different surface morphologies from complete amorphous thin films to hedrites or spherulites embedded in an amorphous layer were obtained by dip coating a substrate in a solution of semi crystalline polymer PLLA. The observed morphology of the PLLA films depended on the withdrawal speed, the nature of the solvent and the molar mass of the PLLA.

High withdrawal speed led to a PLLA layer with a flat surface whatever the solvent and the molar mass without any structuration (Figure 3) and diffraction peak (Figure 6), which were the signatures of amorphous layer in a metastable state. The fact that PLLA amorphous layer in a metastable state was obtained in thin film (less than $1 \mu \mathrm{m}$ ) was to our knowledge only mentioned by Toolan et al. [6] for another polymer (PEO) by spin coating a PEO solution. For bulk material, amorphous PLLA is obtained by cooling a PLLA melt at a rate higher than a critical value as studied by Androsch and Iqbal [10]. In this case, the melt is fully transformed into a "glass" by quickly lowering the temperature below to Tg. They also have demonstrated that this critical cooling rate depends on the molecular mass [10]. The same observation has been done by Hernandez Sanchez et al. [35] who have obtained PLLA amorphous layer, $5 \mu \mathrm{m}$ thick by simply quenching from the melt at low temperatures and have invoked the slow crystallization rate of PLLA. In our case of dip coating process with high withdrawal speed (draining regime), a wet liquid layer was formed when the substrate was removed from the solution. The fast evaporation of the solvent in this regime of deposition (faster in draining regime than in capillary regime [36]) hindered the crystallization of the PLLA (Figure 6) and limited the formation of the spherulites or hedrites (Figure 3). High withdrawal speed dip coating was thus, a simple and straightforward process (one step without post treatment) to prepare amorphous PLLA film.

Spin coating the PLLA100K or PLLA 323K solutions in DCE, DCM and dioxane led to films with characteristic similar to those prepared by dip coating at high withdrawal speeds ( no crystallization peak in GIXRD and flat surfaces in AFM ( AFM images can be seen on figure SM11). As in dip coating at high withdrawal speed, the evaporation of the solvent during the process hindered PLLA crystallization.

At low withdrawal speed, the observed morphology depended on the nature of the solvent and the molar mass of the polymer. For DCE and dioxane, hedrites or spherulites were observed and covered partially or totally a flat polymeric layer. These structures exhibited diffraction peaks at 17.2 and $19.4^{\circ}$ and were consequently crystallized. Crystallization of PLLA has been widely studied in the literature [11,37-38] and leads generally to four types of crystalline 
structures : $\alpha$ - orthorhombic form which is the most common one observed for isothermal and non-isothermal crystallization from the melt and for solution crystallization $[17,38-40], \beta-$ $[38,41]$ and $\gamma$ forms which are two "frustrated forms" [12, 42] obtained by stretching or epitaxial crystallization and finally $\alpha^{\prime}$-form which is a disordered $\alpha$-form obtained crystallization at low temperature [11, 38, 43-44]. The diffraction peaks observed in Figure 6 at 17.2 and $19.4^{\circ}$ can be attributed as usually to (110)/(200) and (203) diffraction peaks of the $\alpha$-form of PLLA [11]. The very weak humps between 12 and $15^{\circ}$ observed could be attributed to others diffraction peaks such as (010), (103) and (004) [11, 17].

For DCM solutions, GIXRD shows no diffraction peaks (PLLA100K) or a broad diffuse signal (PLLA 323K) whereas AFM image reveals perfect spherulites, suggesting a high level of crystallization. This apparent inconsistency may be explained differently in the case of the two molar mass. For $100 \mathrm{~K}$, one needs to consider that the sparely dispersed spherulites only represent a limited fraction of the surface of the film that is in fact composed of a majority of a flat amorphous continuous domain. The crystallization is in this case too low to be detected by GIRXD. For the PLLA 323K, dispersed spherulites were observed on the surface by AFM (Figure 2a). In this case, the surface could be considered as rough since spherulites creates protuberances above the surface as high as $100 \mathrm{~nm}$ high. For DCM PLLA323K, the background line of the diffractogramm was high due to strong X-ray diffuse scattering and the observed peaks were very broad and shifted compared to those observed for DCE and dioxane. The broadness could be explained by very small diffraction zones (short range order diffraction) and the shift of the peaks by the roughness of the surface which modify the real $\mathrm{X}$-ray incident angle and thus the angular position of the diffraction peaks. We could conclude that for DCM these spherulites were weakly crystallized or/and represented a very limited volume fraction.

At low withdrawal speed, the capillary regime dominated the formation of the film (i.e. the upward capillary flow of solution compensated the loss of solvent by evaporation in the meniscus formed by the contact of the substrate and the solution). If the solvent evaporation rate was low, the capillary flow was low leading to thinner films and vice/versa. For DCE and dioxane, evaporation rate and capillary flow of solution were low, leading to thickness under $200 \mathrm{~nm}$ (as seen in Figure 1). In contrast, evaporation rate and capillary flow were high for DCM, leading to thick $(1 \mu \mathrm{m})$ film. It is important to note that the used solutions for Figure 1 had the same polymer concentration $\left(20 \mathrm{mg}_{\mathrm{mL}} \mathrm{m}^{-1}\right)$. This explains why the thicknesses of the 
films prepared with DCM were higher than the thicknesses of the films prepared with DCE and dioxane.

The processes occurring in the meniscus during the deposition can also explain the difference in morphology since the process of nucleation and growth of the crystalline features were highly impacted by the interplay of the evaporation of solvent on one hand and the capillary flow on the other hand. For DCE and dioxane (low evaporation rate), dip coating led to formation of numerous hedrites or spherulites, meaning that that the number of stable nucleation sites was high but the crystallization process was limited. In contrast, the limited number of spherulites observed for DCM indicates that the number of stable nucleation sites was low and the fact that well-developed spherulites with a well-defined circular shape were observed means that the growth of the spherulites was not constrained. These observations can be interpreted by the superposition of the solvent evaporation and capillary flow processes. Stable nuclei were formed by solvent evaporation when the concentration of polymer reached supersaturation. Crystallization growth is the consequence of the macromolecules diffusion towards the crystal interface. In the dip-coating process, the evaporation process initiates a constant supply of "fresh" solution by capillary flow, that brings new macromolecules (that can crystallize) but also new solvent molecules that can destroy the nuclei by dissolution. It can be then understood that the final morphology (number and size of the crystalline features) results from a balance of these two phenomena. If the evaporation rate was low (DCE and dioxane), the capillary flow was low and stable nuclei at the surface were formed with however a slow polymer diffusion that impaired the formation of complete spherulites. If the evaporation rate was high (DCM), capillary flow was high and formed nuclei at the surface were subjected to dissolution but stable nuclei grew up to complete spherulites due to a constant polymers supply. It is interesting to note that despite a perfect visual spherulite structure, XRD indicated a limited degree of crystallinity.

It is known that the morphology developed during crystallization of polymers in confined environment can also be influenced by the thickness of the films [7, 8]. In order to determine whether or not the morphology observed in our case depended on the thickness of the film, the concentrations of the solutions of PLLA 100K in DCM, DCE were adapted in order to obtain the same film thickness $(150 \mathrm{~nm})$ at a given withdrawal speed of $2 \mathrm{~mm} \cdot \mathrm{min}^{-1}$ (i.e. in the capillary regime). The observed surface morphology of the films obtained for these DCE or DCM solutions are given in SM 12 and were the same than those presented in Figure 1 for $20 \mathrm{mg} \cdot \mathrm{mL}^{-1}$ solution. Consequently, the observed morphologies did not depend on the thickness of the film but were related to the evaporation rate of the solvent. 
Let now discuss the evolution of an amorphous PLLA thin film under annealing conditions (thermal annealing at $80^{\circ} \mathrm{C}$ or solvent vapor annealing). Thermal annealing at $80^{\circ} \mathrm{C}$ induced the crystallization of PLLA as demonstrated by GIXRD. However, the diffractogram exhibited only one strong diffraction peak at $16.5^{\circ}$ in the studied range, which was different from what we observed directly after dip coating. This can be due to the formation of $\alpha^{\prime}$ form which is a disordered $\alpha$ form observed for crystallization at low temperature [11, 38, 43-44]. This $\alpha^{\prime}$ form has a pseudo-hexagonal structure [11]. The presence of only one diffraction peak in the studied range of angles can be explained by the extinction rule of the hexagonal structure. This peak can be indexed as (010). For the $\alpha^{\prime}$ form, a and b-axes are dilated compared to those of $\alpha$ form. This could explained the lower diffraction angle $16.5^{\circ}$ for $(010)$ diffraction peak of the $\alpha^{\prime}$ form compared to $17.2^{\circ}$ for (110) and (200) diffraction peaks of the $\alpha$ form.

DCE solvent vapor exposure of an amorphous PLLA layer led to formation spherulites with the same XRD $\alpha$-form signature than dip-coated film. Further DCM exposure of an already DCE exposed film led to flat amorphous layer (and vice-versa). During exposure, the film swelled as a result of a solvent penetration in the film that also renders the PLLA chains mobile. Opening the exposure cell led to solvent evaporation from the film and deswelling of the film. Crystallization of PLLA film induced by solvent vapor exposure has been studied by some authors [19, 23-24]. Wu et al. have studied the solvent vapor exposure of ultra-thin film $10 \mathrm{~nm}$ thick of PLLA 380K and compared the efficiency of acetone, DCM and chloroform to provoke crystallization [23-24]. Acetone and chloroform lead to crystallization whereas DCM leads to an amorphous layer. They have attributed this difference of behavior to the difference of affinity of the solvent toward PLLA (acetone and chloroform have weak interactions with PLLA that allows crystallization whether DCM has strong interaction with PLLA that induces redissolution of formed crystallites). In our case, PLLA exhibited the same swelling ratio of 1.9 in DCM and DCE vapor leading to the conclusion that DCM and DCE had the same affinity toward PLLA [45]. According to the results obtained by Wu et al. [23-24], this should lead to a similar crystallization behavior which is not what we observed. Because DCE and DCM vapor pressures are strongly different (respectively $87 \mathrm{hPa}$ and $573 \mathrm{hPa}$ ), the evaporation rate during the swelling steps and drying steps must be considered in our case. During solvent exposure, the solvent evaporates above the liquid and swells the film. During the opening of the exposure device, the solvent in the film evaporates. To induce crystallization during solvent vapor exposure, solvent vapor must induce sufficient swelling 
of the film and during opening of the exposure device formation of crystalline structures. For DCE, solvent vapor exposure must long enough (more than $5 \mathrm{~min}$ ) to allow a sufficient swelling of the film and upon drying during opening of the exposure device, the slow evaporation of the DCE solvent allowed spherulites to be formed. For DCM, solvent evaporation is faster, the film swells quicker and more than for DCE, formed spherulites by DCE solvent vapor exposure are redissolved under vapor exposure and the evaporation is too fast to allow form. Note that in our case, the films were much thicker than those studied by Wu et al. $[23,24]$.

\section{Conclusion}

In this work, we have shown that dip-coating at various deposition rate can be used to obtain PLLA thin films $(20 \mathrm{~nm}-1 \mu \mathrm{m})$ with various crystalline organizations.

Firstly, preparation of amorphous thin films of PLLA with different thicknesses was achieved using dip coating at high withdrawal speed (independently on the used solvent). We showed that these films could be crystallized upon post-treatments such as thermal annealing or DCE vapor exposure. Interestingly, a reversible crystalline/amorphous conversion upon DCM vapor exposure could be obtained and was attributed to the low/high evaporation rate of the solvents (DCE/DCM) favoring or impairing the spherulites formation.

Secondly, semi-crystalline films were obtained in the capillary regime (low withdrawal speed) and their actual morphology (hedrites up to well-defined spherulites) and crystallinity degree were found to be directly related to the withdrawal speed, the molar mass and solvent nature. The process of nucleation and growth of the crystalline features was shown to be the result of the interplay of the evaporation of solvent on one hand and the capillary flow on the other hand. Large sparely dispersed poorly crystallized spherulites were formed at high evaporation rate (DCM), due to the high capillary flow of solvent that compensated the large evaporation rate. In contrast, crystallized spherulites and hedrites were observed at low evaporation rate (DCE and dioxane), with characteristic peaks of the PLLA $\alpha$-form. In this case, the capillary flow was low allowing more crystallized structures with better crystallization to be formed. Increased molar mass reduces the macromolecular mobility, thus limiting the crystallization process. 


\section{Acknowledgments}

Pascal Andréazza is thanked for his guidance with the Grazing Incidence X-Ray diffraction. We gratefully acknowledge the financial support provided to the PIVOTS project by the Région Centre - Val de Loire (ARD 2020 program and CPER 2015 -2020) and the French Ministry of Higher Education and Research (CPER 2015 -2020 and public service subsidy to CNRS and Université d'Orléans). 


\section{References}

[1] C.J. Brabec, M. Heeney, I. McCulloch, J. Nelson, Influence of blend microstructure on bulk heterojunction organic photovoltaic performance. Chem Soc Rev. 40 (2011) 1185-1199. http://dx.doi.org/10.1039/c0cs00045k.

[2] M.A. Ruderer, C. Wang, E. Schaible, A. Hexemer, T. Xu, P. Mu Morphology and Optical Properties of P3HT:MEH-CN-PPV Blend Films. Macromolecules., 46 (2013)4491-4501, http://dx.doi.org/10.1021/ma4006999.

[3] R. Meier, M. Ruderer, A. Diethert, Influence of film thickness on the phase separation mechanism in ultrathin conducting polymer blend films. J Phys Chem B. 115 (2011)28992909. http://dx.doi.org/10.1021/jp200341u.

[4] R. Auras, B. Harte, and S. Selke, An Overview of Polylactides as Packaging Materials,. Macromol. Biosci. 4 (2004). 835-864. http://dx.doi.org/10.1002/mabi.200400043

[5] S. Andjelic, R.C. Scogna, Polymer crystallization rate challenges: The art of chemistry and processing. J. Appl. Polym. Sci. 132 (2015) 1-15. http://dx.doi.org/10.1002/app.42066.

[6] D.T.W. Toolan, A. Isakova, R. Hodgkinson, N. Reeves-McLaren, O.S. Hammond, K.J. Edler,W. H. Briscoe, T. Arnold, T. Gough, P. D. Topham and J. R. Howse, Insights into the Influence of Solvent Polarity on the Crystallization of Poly(ethylene oxide) Spin-Coated Thin Films via in Situ Grazing Incidence Wide-Angle Xray Scattering. Macrolecules. 49 (2016) 4579-4586. http://dx.doi.org/10.1021/acs.macromol.6b00312.

[7] R.E. Prud'homme Crystallization and morphology of ultrathin films of homopolymers and polymer blends. Prog Polym Sci. 54-55 (2016) 214-231.

http://dx.doi.org/10.1016/j.progpolymsci.2015.11.001.

[8] C. Yu, .Q.Xie, Y. Bao, G. Shan, P. Pan, Crystalline and Spherulitic Morphology of Polymers Crystallized in Confined Systems. Crystals 7(2017)147.

http://dx.doi.org/10.3390/cryst7050147.

[9] D. Garlotta, A Literature Review of Poly ( Lactic Acid ). J Polym. Environ. 9 (2002) 6384.

[10] R. Androsch and H.M.N. Iqbal, C. Schick, Non-isothermal crystal nucleation of poly (1lactic acid). Polymer 81( 2015) 151-158. http://dx.doi.org/10.1016/j.polymer.2015.11.006.

[11] T. Kawai, N. Rahman, G. Matsuba, K.Nishida, T. Kanaya, M. Nakano, H.Okamoto, J. Kawada, A. Usuki, N.Honma, K. Nakajima, and M. Matsuda, Crystallization and melting 
behavior of poly (L-lactic acid). Macromolecules 40 (2007) 9463-9469.

http://dx.doi.org/10.1021/ma070082c.

[12] L. Cartier, T. Okihara, Y. Ikada, H. Tsuji, J. Puiggali and B. Lotz ,Epitaxial crystallization and crystalline polymorphism of polylactides. Polymer 41(2000)8909-8919. http://dx.doi.org/10.1016/0032-3861(94)90933-4.

[13] B.A. Lotz Single crystals of the frustrated $\beta$-phase and genesis of the disordered $\alpha^{\prime}$-phase of poly(1 -lactic acid). ACS Macro Lett. 4 (2015) 602-605.

http://dx.doi.org/10.1021/acsmacrolett.5b00205.

[14] K. Wasanasuk and K. Tashiro, Crystal structure and disorder in Poly(L-lactic acid) $\delta-$ form ( $\alpha^{\prime}$ form) and the phase transition mechanism to the ordered $\alpha$ form. Polymer 52 (2011) 6097-6109. http://dx.doi.org/10.1016/j.polymer.2011.10.046.

[15] K. Wasanasuk and K. Tashiro, Structural regularization in the crystallization process from the glass or melt of poly(L-lactic acid) viewed from the temperature-dependent and time-resolved measurements of FTIR and wide-angle/small-angle X-ray scatterings.

Macromolecules 44 (2011) 9650-9660. http://dx.doi.org/10.1021/ma2017666.

[16] Y. Kikkawa, H. Abe, T. Iwata, Y. Inoue, Y. Doi, Crystallization, Stability, and Enzymatic Degradation of Poly( 1 -lactide) Thin Film. Biomacromolecules. 3 (2002) 350-356. http://dx.doi.org/10.1021/bm015623z.

[17] S.T. Hsu, Y. L. Yao, Effect of Film Formation Method and Annealing on Morphology and Crystal Structure of Poly ( L-Lactic Acid ) Films. J Manuf. Sci. Eng. 136 (2014) 1-9. http://dx.doi.org/10.1115/1.4025909.

[18] M. Yasuniwa, S. Tsubakihara, K. Iura, Y. Ono, Y. Dan, and K. Takahashi, Crystallization behavior of poly(l-lactic acid), Polymer 47 (2006) 7554-7563.

[19] N. Naga, Y. Yoshida, M. Inui, K.Noguchi, S. Murase, Crystallization of Amorphous Poly(lactic acid) Induced by Organic Solvents. J Appl Polym Sci. 119 (2011) 2058-2064. http://dx.doi.org/10.4236/ojpchem.2013.32006

[20] A. Udagawa, T. Fujie, Y. Kawamoto, A. Saito, S. Takeoka, T. Asahi, Interfacial effects on the crystallization and surface properties of poly(l-lactic acid) ultrathin films. Polym J. (2015) 1-5. http://dx.doi.org/10.1038/pj.2015.95

[21] M.L Di. Lorenzo, C. Silvestre, Non-Isothermal Crystallization of Polymers. Prog. of Polym. Sci. 24.(1999)917-950. https://doi.org/10.1016/S0079-6700(99)00019-2.

[22]S. Sato, D. Gondo, T. Wada, S. Kanehashi, K. Nagai. Effects of various liquid organic solvents on solvent-induced crystallization of amorphous poly(lactic acid) film. J Appl Polym Sci.129 (2013)1607-1617. http://dx.doi.org/10.1002/app.38833 
[23] N.Wu, S. Lang, H. Zhang, M. Ding, J. Zhang, Solvent-induced crystallization behaviors of PLLA ultrathin films investigated by RAIR spectroscopy and AFM measurements. $J$ Phys Chem B. 2014;118(2014):12652-12659. http://dx.doi.org/10.1021/jp506840e.

[24] N. Wu, M. Ding, C. Li, Y. Yuan, J. Zhang, Lamellar orientation and crystallization dynamics of poly (L-lactic acid) thin films investigated by in-situ reflection absorption infrared spectroscopy. J Phys Chem B. 2011;115(40):11548-11553.

http://dx.doi.org/10.1021/jp203110u.

[25] P. Shaiju, N.S. Murthy and E.B. Gowd. Molecular, Crystalline, and Lamellar LengthScale Changes in the Poly(l-lactide) (PLLA) during Cyclopentanone (CPO) Desorption in PLLA/CPO Cocrystals. Macromolecules. 49 (2016) 224-233.

http://dx.doi.org/10.1021/acs.macromol.5b02425.

[26] P. Rizzo, G. Ianniello, V. Venditto, O. Tarallo, G. Guerra, Poly(1 -lactic acid): Uniplanar Orientation in Cocrystalline Films and Structure of the Cocrystalline Form with Cyclopentanone. Macromolecules. 48 (2015)7513-7520.

http://dx.doi.org/10.1021/acs.macromol.5b00908.

[27] H. Marubayashi, S. Asai, M. Sumita Complex Crystal Formation of Poly(L-lactide) with Solvent Molecules. Macromolecules. 45 (2012) 1384-1397.

http://dx.doi.org/10.1021/ma202324g.

[28] Q. Lan and Y. Li, "Mesophase-mediated crystallization of poly(1 -lactide): Deterministic pathways to nanostructured morphology and superstructure control," Macromolecules, 49 (2016) 7387-7399. http://dx.doi.org/10.1021/acs.macromol.6b01442

[29] R.Z. Rogowski, A.A. Darhuber, Crystal growth near moving contact lines on homogeneous and chemically patterned surfaces. Langmuir 26 (2010) 11485-11493.

http://dx.doi.org/10.1021/la101002x

[30] M. Faustini, B. Louis, P.A. Albouy, M. Kuemmel, D. Grosso, Preparation of Sol-Gel Films by Dip-Coating in Extreme Conditions. J. Phys Chem C. 114 (2010)7637-7645. http://dx.doi.org/10.1021/jp9114755

[31] K. Taguchi, A. Toda, Y. Miyamoto, Crystal Growth of Isotactic Polystyrene in Ultrathin Films : Film Thickness Dependence. J Macromol Sci Part B Phys. 45 (2006) 1141-1147. http://dx.doi.org/10.1081/MB-120013081.

[32]. Y. Akpal and E.J. Amis Evolution of density fluctuations to lamellar crystals in linear polyethylene. J Chem Phys. 111(1999)8686-8695. http://dx.doi.org/10.1063/1.480208.

[33] B. Crist, J.M. Schultz, Polymer spherulites: A critical review. Prog Polym Sci. 56 (2016) 1-63. http://dx.doi.org/10.1016/j.progpolymsci.2015.11.006. 
[34] G.N. Patel, R.D. Patel. Growth mechanism of polymer hedrites. Eur Polym J. 6 (1970) 657-658. http://dx.doi.org/10.1016/0014-3057(70)90015-7

[35] F. Hernandez Sanchez, J. Molina Mateo, F.J. Romero Colomer, M, Salmerón Sánchez, J.L. Gómez Ribelles and J.F. Mano, Influence of low-temperature nucleation on the crystallization process of poly(L-lactide). Biomacromolecules 6 (2005)3283-3290. http://dx.doi.org/10.1021/bm050323t.

[36] A. Vital, M. Vayer, T. Tillocher, R. Dussart, M. Boufnichel, C. Sinturel, Morphology control in thin films of PS:PLA homopolymer blends by dip-coating deposition. Appl Surf Sci. 393 (2017) 127-133. http://dx.doi.org/10.1016/j.apsusc.2016.09.151

[37] P. Pan, W. Kai, B. Zhu, T. Dong, Y. Inoue, Polymorphous Crystallization and Multiple Melting Behavior of Poly (L -lactide): Molecular Weight Dependence. Macromlecules 40 (2007) 6898-6905. http://dx.doi.org/10.1021/ma071258d

[38] P. Pan, Z. Liang, B. Zhu, T. Dong, Y. Inoue, Blending Effects on Polymorphic Crystallization of Poly ( 1-lactide ) Blending Effects on Polymorphic Crystallization of Poly ( L -lactide ). Macromolecules 42 (2009) 3374-3380 http://dx.doi.org/10.1021/ma8024943.

[39] P. De Santis, A.J.Kovacs Molecular conformation of poly(S-lactic acid). Biopolymers. 6 (1968) 299-306. http://dx.doi.org/10.1002/bip.1968.360060305

[40] S. Sasaki, T. Asakura, Helix Distortion and Crystal Structure of the $\alpha$-Form of Poly(1lactide) Macromolecules 36 (2003) 8385-8390. http://dx.doi.org/10.1021/ma0348674

[41] B. Eling, S. Gogolewski, A. Pennings, Biodegradable materials of poly(L-lactic acid): 1. Melt-spun and solution-spun fibres Polymer 23 (1982) 1587-1593.

https://doi.org/10.1016/0032-3861(82)90176-8

[42] J. Puiggali, Y. Ikada, H. Tsuji, L. Cartier, T. Okihara, B. Lotz The frustrated structure of poly(l-lactide). Polymer $41 \quad$ (2000) 8921-8930. $\quad$ http://dx.doi.org/10.1016/S0032$\underline{3861(00) 00235}$

[43] E. Meaurio, I. Martinez De Arenaza, E. Lizundia, J.R. Sarasua Analysis of the C=O stretching band of the $\alpha$-crystal of poly(L-lactide). Macromolecules. 42 (2009) 5717-5727. http://dx.doi.org/10.1021/ma9008109.

[44] J, Zhang H. Tsuji, I. Noda, Y. Ozaki. Structural changes and crystallization dynamics of poly(L-lactide) during the cold-crystallization process investigated by infrared and twodimensional infrared correlation spectroscopy. Macromolecules. 37 (2004) 6433-6439. http://dx.doi.org/10.1021/ma049288t. 
[45] M. Vayer, A. Vital and C. Sinturel, New insights into polymer-solvent affinity in thin films, European Polymer Journal 93 ( 2017) 132-139.

https://doi.org/10.1016/j.eurpolymj.2017.05.035 
